\title{
When Heritage Is Rural: Environmental Conservation, Cultural Interpretation and Rural Renaissance in Chinese Listed Villages
}

\author{
Anna-Paola Pola \\ World Heritage Institute of Training and Research for the Asia and the Pacific Region under the Auspice of UNESCO \\ (WHITRAP), Shanghai, China \\ Email: ap.pola@whitr-ap.org
}

\begin{abstract}
This article argues that China's growing attention towards villages in recent years has contributed to transforming the concept of built heritage and helped in disseminating a holistic idea of territory that has prepared the ground for the environmental turn the country is now experiencing. This conceptual transformation was carried on by a number of converging-although independent-initiatives from different governmental institutions and has been driven by different factors, most importantly, the need to mend the development gap between urban and rural areas, and the wish to rediscover the cultural heritage of the country. The Chinese experience in village preservation was conceived as an important component of a much wider corpus of measures, driven by the rural revitalisation discourse, and should therefore be situated within this broader conceptual framework. This perspective leads to a distinctive approach to the concept of heritage and outlines a type of protection 'with Chinese characteristics' that will increasingly influence the international context. Drawn on three years of field observations and desk analysis, the article highlights some of the characters that define the Chinese experience in village preservation, analysing the most important national lists of villages and examining various cases.
\end{abstract}

KEYWORDS rural development, rural heritage, beautiful villages, historic cultural villages, traditional villages, ecovillages, rural tourism, rural revitalisation

Received April 15, 2019; accepted May 14, 2019.

\section{Introduction}

During the past 15 years, the focus on villages and rural areas in China has transformed the concept of built heritage, extending it from monuments and historical architectures to include a much richer range of values. This more comprehensive idea of heritage considers that the culture embedded in a place shapes its built environment through many elements: its position and relation with the landscape, local agricultural patterns and practices, urban layout, social organisation, building techniques, customs and legends animating people's lives. Within a few years, all these attributes have been acknowledged and incorporated into official discourses, policies, and practices. In this framework, the concept of rural heritage has acquired a new relevance integrating its multiple components: the landscapes (carved out over centuries by people living off the land and using its available natural resources); the settlements (built following traditional techniques, materials and beliefs); the products (adapted to local conditions and needs); the techniques, tools and know-how ('that have made creative activity possible and which remain essential for maintaining, restoring, changing and modernising' its outputs, in accordance with 'the design logic and aesthetic of the buildings/environment/ landscape as a whole' [CEMAT 2003]).

A number of initiatives, conceived independently one from another, and promoted by different government institutions, have contributed to this conceptual shift. The transformation has been driven by two main factors: the need to mend the development gap between urban and rural areas, and the will to rediscover the cultural heritage of the country. Hence, the Chinese experience in village preservation was conceived as a component of a much wider corpus of measures, driven by the rural revitalisation discourse. Accordingly, the heritage narrative has been reconceptualised to fit priorities that at first glance 
may not appear to be directly connected with heritage, such as poverty alleviation and rural development (Lincoln and Madgin 2018).

This revised, enriched approach to heritage has acted as an enabler leading to further important shifts. Broadening heritage perspective and meaning has notably helped disseminate a holistic idea of territory (eco-system), through a cultural-historical-natural approach (Han 2018) that prepared the ground for the environmental turn that the country is now experiencing.

This heritage protection 'with Chinese characteristics' drew on contemporary national needs and specific interpretations of Chinese culture in order to create a vision for the future which is rooted in national identity (Hansen et al. 2018). Overall, this complex background outlines a type of heritage protection that is more attentive to the role of culture in promoting regional and ethnic differences, local knowledge and environmental management practices, fostering poverty alleviation, economic development and innovation.

The Chinese experience is expected to increasingly influence the international context, grounding the theoretical insight raised in the goals of the 2030 Agenda for Sustainable Development (United Nations 2015) on empirical evidence and concrete indicators.

To outline this trajectory, since the creation of national lists of exemplary settlements has become a key feature in domestic practices (Maags 2018), the article analyses the transformations which have occurred in the narratives and in the requirement standards for villages to be included into these lists. The lists are managed, individually or jointly, by different government departments ${ }^{1}$, and respond to diverse scopes (agricultural modernisation and infrastructural improvement, tourism promotion, heritage protection and education, environmental conservation). Some lists include villages considered exemplary models (Beautiful Villages), while others identify an administrative object (Historic and Cultural Villages). Though there are major differences, the required standards for inscription constitute a set of indicators crucially expressing the elements of concern at different stages of the rural revitalisation process for different government offices.

The most important lists have been reviewed: Beautiful Villages, Historical and Cultural Villages, Traditional Villages, Beautiful Leisure Villages, and Ecological Villages (Eco-civilisation Villages). The analysis follows as much as possible-because themes and dates often overlap-a thematic and chronological order. Each paragraph is further explained by a case study that exemplifies the subject.

\section{The Rural Revitalisation Discourse}

In recent years, interest in rural areas and small settlements has been growing exponentially in China. This is part of a global phenomenon. All around the world, initiatives promoting the enhancement and development of villages and small towns are becoming increasingly frequent.

Small settlements reflect an articulated, fine-tuned interaction-developed throughout time-between humankind and the natural environment. This relationship has shaped unique landscapes, multiple cultures and belief systems, and influenced social and spatial organisation.

Today, however, these territories are undergoing dramatic transformations. Villages are experiencing out-migration and marginalisation, loss of cultural and biological diversity, and their surrounding landscapes are witness to a revolution in farming, infrastructure and energy production to meet the needs of the world's population. In the words of Achim Steiner, United Nations Development Programme, and Shenggen Fan, Director General of the International Food Policy Research Institute (IFPRI), 'Rural residents make up $45 \%$ of the world's population but bear a disproportionate burden of poverty, malnutrition, and poor quality of life ... Rural areas lag behind urban areas in reducing rates of child stunting (low height for age). Many rural environments lack basic services such as education; health; roads; water and sanitation; and suffer from rising pollution levels and dwindling natural resources. These challenges will only be exacerbated by climate change.' (Steiner and Fan 2019)

Yet, the critical role played by villages, small towns, and their vast surrounding environment is now becoming acknowledged as a complementary counterpart to growing cities, acting as extraction sites, reservoirs for food, fresh water, air, and as leisure spaces. UNESCO is promoting the 'Ruritage' programme, a project funded by the European Community to create innovative, rural regeneration-based models for cultural and natural heritage. The programme looks for experiences and indicators to consolidate the role of culture as the fourth pillar of sustainable development and to contribute to economic growth, social inclusion, and environmental sustainability in rural areas (Ruritage 2019).

China is developing its own methods of rural revitalisation, investing in rural economies not only as propellers for national and global values but also as providers of quality environmental services and leisure (Steiner and Fan 2019). Although it has its own unique characteristics, China provides a privileged vantage point to observe this global phenomenon. For millennia, the country was an 
agriculture empire, marked by a dense network of rural settlements safeguarding the territory. The Chinese countryside played a crucial role in the history of the country, and an incredible amount of testimonies of its millenary history still marks its land, rural settlements, old routes, watercourses and hydraulic works.

The recent national focus on small settlements answers to a complex set of motivations. The need for rural economic development, the hope of improving people's livelihoods, the rediscovery of historical heritage, the interpretation of local and national identities, and the promotion of tourism all overlap, continuously redefining and improving the contents and objectives of the initiative.

In the early 2000s, after two decades of economic reform and intense urban development, increasing discontent due to the income gap between rural and urban areas drew national attention. Agriculture, villages and farmers were designated as the 'Three Rural Problems', and a series of policies was introduced in the following years to address these issues and mend the gap. In October 2017, at the $19^{\text {th }}$ National Congress of the Chinese Communist Party, the unbalanced development between rural and urban areas remained highlighted as a main contradiction for the country's aims of accomplishing a 'moderately prosperous society', thus the focus was set on poverty eradication by 2020 (Xi 2017).

The Chinese model of development is closely tied to the urbanisation process. The law states that 'urbanisation is the only way to modernisation' (State Council 2014), therefore, the measures to address the imbalance must involve the application and coordination of planning practices. In 2003, the Five Types of Coordinated Planning law was released. In 2006, the policy 'Build a New Socialist Countryside' was approved within the framework of the $11^{\text {th }}$ Five Year Plan. The strategy calls for reaching urban standards of living in rural areas and commits local officials to apply planning practices to villages and regions in order to achieve this goal. Accordingly, in 2007, the 1990 Urban Planning Law was revised, becoming the Urban and Rural Planning Law. At the same time, the government launched reforms to boost the economy on a large scale. These measures transformed the rural land management system and made efforts to modernise the farming sector (the centuries-old agricultural tax was abolished in 2006). Furthermore, the government incentivised entrepreneurial innovation (in 2009, Taobao villages were launched) and provided funds to encourage educated young people and entrepreneurs to return to their home villages to make innovative investments in rural areas
(State Council 2015, 2016). Tourism, and rural tourism, in particular, received a strong boost. These measures culminated with the National Rural Revitalisation Strategic Plan in 2018.

\section{A New Image for the Countryside- Beautiful Villages}

As part of the Build a New Socialist Countryside policy, the Beautiful Villages program was proposed to improve the village environment on a wider scale. The strategy aims to rationalise village planning and layout, building infrastructure (roads), and providing clean water and sewage. It includes the protection of natural and cultural resources, the improvement of ecological sustainability (in terms of renewable energy and energy saving), and the reduction of pollution from agriculture, industry, and houses. Furthermore, the Guidelines for the Construction of Beautiful Villages fosters the modernisation of agriculture and the construction of public services (schools, clinics, post offices). It also considers townscape amelioration in public spaces and greenery (AQSIQ and CNCA 2015).

Anji County in Zhejiang Province originally developed this program in 2008, and a few years later the whole Province implemented the strategy. Quickly perceived as a model, it was applied in other provinces and then became a national policy, promoted by the Ministry of Agriculture, with growing funding support for villages. In 2012, the idea to build Beautiful Villages was deemed so relevant that it was extended from villages to the entire country, becoming the Beautiful China (meili zhongguo) strategy (Lincoln and Madgin 2018).

Worth noting is the discourse on village heritage. Although it is not the focus of this list, the heritage preservation attitude is found in all documents: one of the first 10 Beautiful Villages was expressly devoted to cultural heritage (MOF 2014), and the Guidelines for the Construction of Beautiful Villages (SAC 2014) quotes among its main references both the Convention for the Protection of the World Cultural and Natural Heritage and the Law of the People's Republic of China on Intangible Cultural Heritage. Accordingly, the Guidelines emphasise the importance of local resources, protection, and inheritance of traditional culture and regional characteristics (AQSIQ and CNCA 2015).

Of particular relevance is that rural heritage is considered as part of a comprehensive concept of heritage that includes natural and cultural resources recognised as a unique asset to be safeguarded for a better 'ecological development'. The analysis of the official documents thus presents an idea of ecology comprising natural 
environment, cultural heritage, and ecological sustainability (energy efficiency, pollution constraint). All these components are mobilised to secure the socio-economic development of the village. Interestingly, in the report of Lincoln and Madgion (2018), the same considerations are confirmed in the government officials' discourse for the case of Anji County, where the idea of Beautiful Villages started in 2008. In time, this approach developed, broadening its scopes and converged in the paradigm of Ecological Civilisation that is the current conceptual framework that embraces and consistently keeps together these considerations and their further adjustments.

\section{Villages in the Landscape}

The nexus between environment and cultural attributes appears, in the bud, in an interesting project that started just before the experiences mentioned above. In June 2003, the Zhejiang Provincial Government launched 'One Thousand Model Villages, Ten Thousand Renovated Villages', a project that played a pivotal role in the development of rural revitalisation. 'The broad objectives of this program were to upgrade village public services and infrastructure and to remediate the problem ... of rural environments' (Bray 2013, 56). The project pioneered technical standards and practices for renovating small settlements and became a reference for the national program Build a New Socialist Countryside.

The comprehensive renovation of the Villages in the landscape, in the West Lake area of Hangzhou, exemplifies the effect of this program. The West Lake Sub-district covers $48 \mathrm{~km}^{2}$; in 2002, it was placed under the jurisdiction of the West Lake Scenic Area (National Park) that became a World Heritage site in 2011. The region has nine villages, six communities, and three agricultural cooperatives, with a population of over 30,000 people. It sits in an important area for the production of West Lake Longjing tea, the most important source of income for villagers. Tea plantations cover about 460 ha and are surrounded by more than 2,000 ha of forest. Its villages have a rich heritage consisting of monuments, traditional buildings, mountain streams, and old trees, but faced issues related to the presence of dilapidated houses, illegal constructions, environmental pollution (water in particular), backward infrastructure, and inadequate sanitation.

Since 2003, the Sub-district implemented the "Villages in the Landscape" project in the framework of the Comprehensive Protection Plan for the West Lake (2003-2007). The project defined an 'environmental management mode': - Planning procedures. Village plans were drafted with the collaboration of experts (in landscape, architecture, urban planning, cultural heritage, and ecological environment) and implemented through a public participation process;

- Local features. Following the general principle: 'Minimum intervention, authenticity, ecological priority', the project focused on protection and renovation. The specific assets of each village were highlighted to diversify the appeal of the different settlements: for instance, Longjing village, rich in historical sites related to the origin of Longjing Tea, enhanced its humanistic and cultural connotations, while Meijiawu village focused on tea gardens, natural environment and local agricultural products;

- Effective use of funds. Government funds were used only for the activities directly managed by the government (urban planning, infrastructure, and implementation coordination), while all other actions (housing renovation, deconstruction of illegal buildings, maintenance ...) depended on private initiative supported by incentives.

The mechanisms of implementation of the project defined clear priorities (preserve the townscape, improve the environment, and raise the standards), and set up a 'management department office'-in charge of supervision and training of local residents on sustainable requirements and administrative procedures - and a 'tea house association' to help people starting tourism-related activities.

The relevant results obtained are: $84,800 \mathrm{~m}^{2}$ of illegal construction demolished, $116,000 \mathrm{~m}$ of underground infrastructure completed, 60,000 trees planted, and more than 2,100 houses renovated.

Overall, the experience of "Villages in the Landscape" showed that the improvement of the environment not only enhanced the living conditions of the residents, but also brought unprecedented opportunities to the local economy, promoting, in particular, tourism and tea branding. Worth noting is that the coordination of every village into a wider strategy, comprising other settlements, landscape, agricultural products, and natural environments, settled a conceptual approach to village plans which is intended to have an increasingly important role.

Longjing tea plantations, initially included in the nominated property for inscription on the World Heritage nomination, were eventually taken away and moved to the buffer zone (Zhang and Taylor 2019). Despite not being the focus of the West Lake Cultural Landscape World Heritage designation the villages in the West Lake area crucially sustain the existence and continuity of 


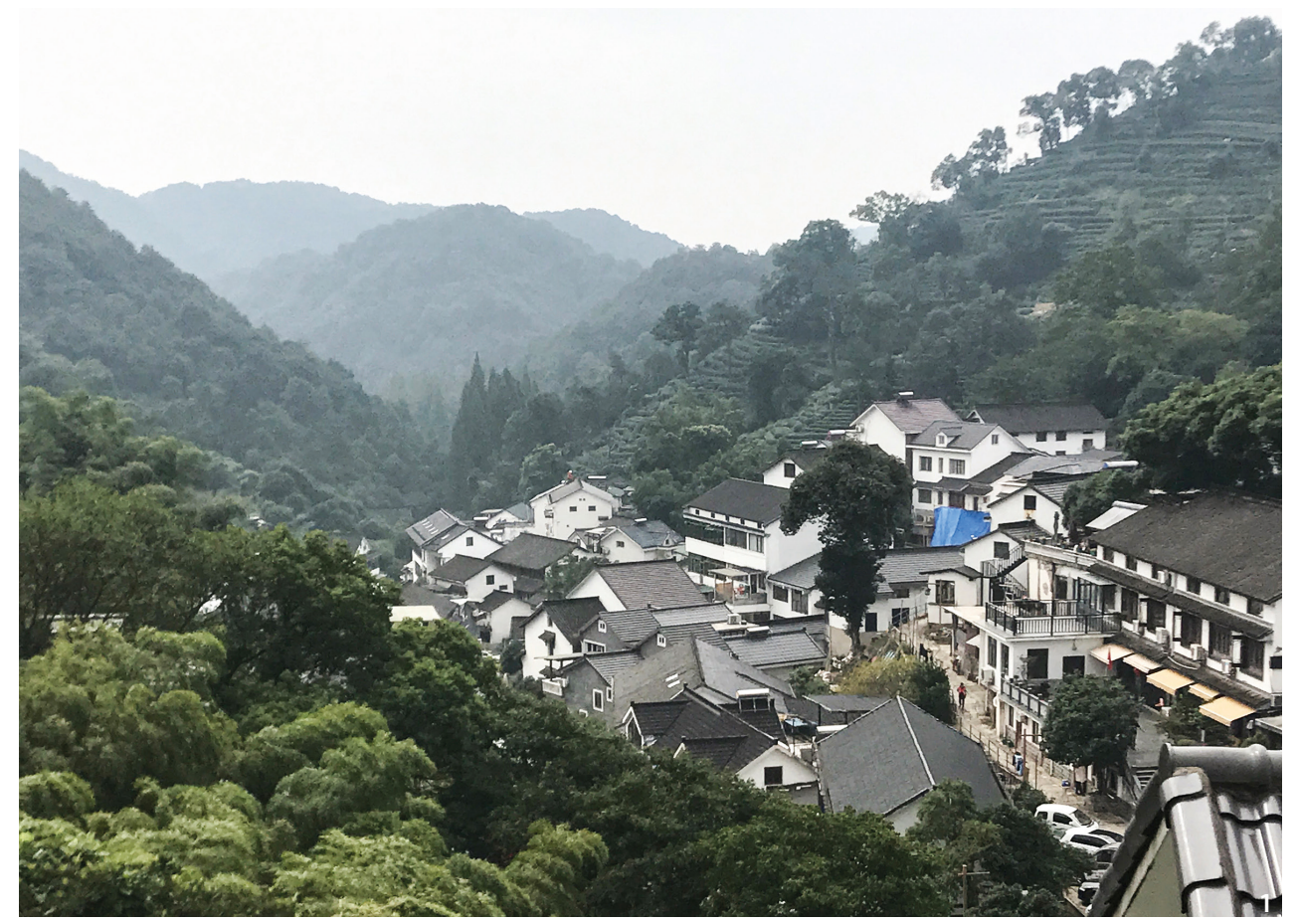

Figure 1 Yangmeiling village, West Lake District, Hangzhou, Zhejiang Province, November 2017 (Source: the author).

the plantation, production, and customs of traditional Longjing tea (Figure 1).

\section{Rural Heritage Values-Historical Cultural Villages, and Traditional Villages}

\section{Xidi and Hongcun}

In 2000, two small settlements in southern Anhui Province, Xidi and Hongcun, were declared World Heritage Sites (WHC 2000). It was a significant moment, as it was the first time that the historical and cultural value of a village in China had been recognised at this level. The combination of reasons that made these two villages and other settlements in the area so rich in ancient buildings and at the same time so well preserved is quite exceptional (ICOMOS 2000). Ancient Huizhou Prefecture, in the region where Anhui and Jiangxi provinces come together, is famous for being home to a powerful group of businessmen who became prosperous during the Ming Dynasty (1368-1644) due to the sale of timber, tea, salt, and other products. An extensive communication network, watercourses and postal routes, favoured the development of long-distance trade. Huizhou 'travelling merchants' used to work in the most flourishing cultural centres of the period, and they built in their home villages a remarkable ensemble of ancestral temples, schools, paved roads, bridges, memorial halls, and luxurious houses for the family remaining there and for their retirement. In the $20^{\text {th }}$ century, when modern roads replaced the ancient network, this pocket of land enclosed by mountains remained excluded from the developing urban areas. Their isolated position and archaic infrastructure, however, had the effect of protecting them from the demolitions and reconstructions that took place in many other areas of the country. Moreover, the high quality of the materials used by the rich merchants for these constructions contributed to protecting them from natural decay. Indeed, the motivations given for the inclusion of Xidi and Hongcun on the World Heritage List (WHL) specifically mention that: 'The two traditional villages ... preserve to a remarkable extent the appearance of non-urban settlements of a type that have largely disappeared or have been transformed in the past century. Their street patterns, their architecture and decoration, and the integration of houses with comprehensive water systems are unique survivals.' (MOC and NACH 2000)

The undeniable architectural and cultural value of these villages is palpable, but it is noteworthy that their inscription on the WHL completely modified the perception of the value of vernacular buildings, rural settlements, and landscapes. While previously, rural environments and traditional lifestyles were considered hindrances to modern development and progress, and villages were either abandoned or drastically overhauled, the relevance of traditional rural heritage has since been recognised and progressively defined based on a continuously developing set of values. The rapid development of National Lists 


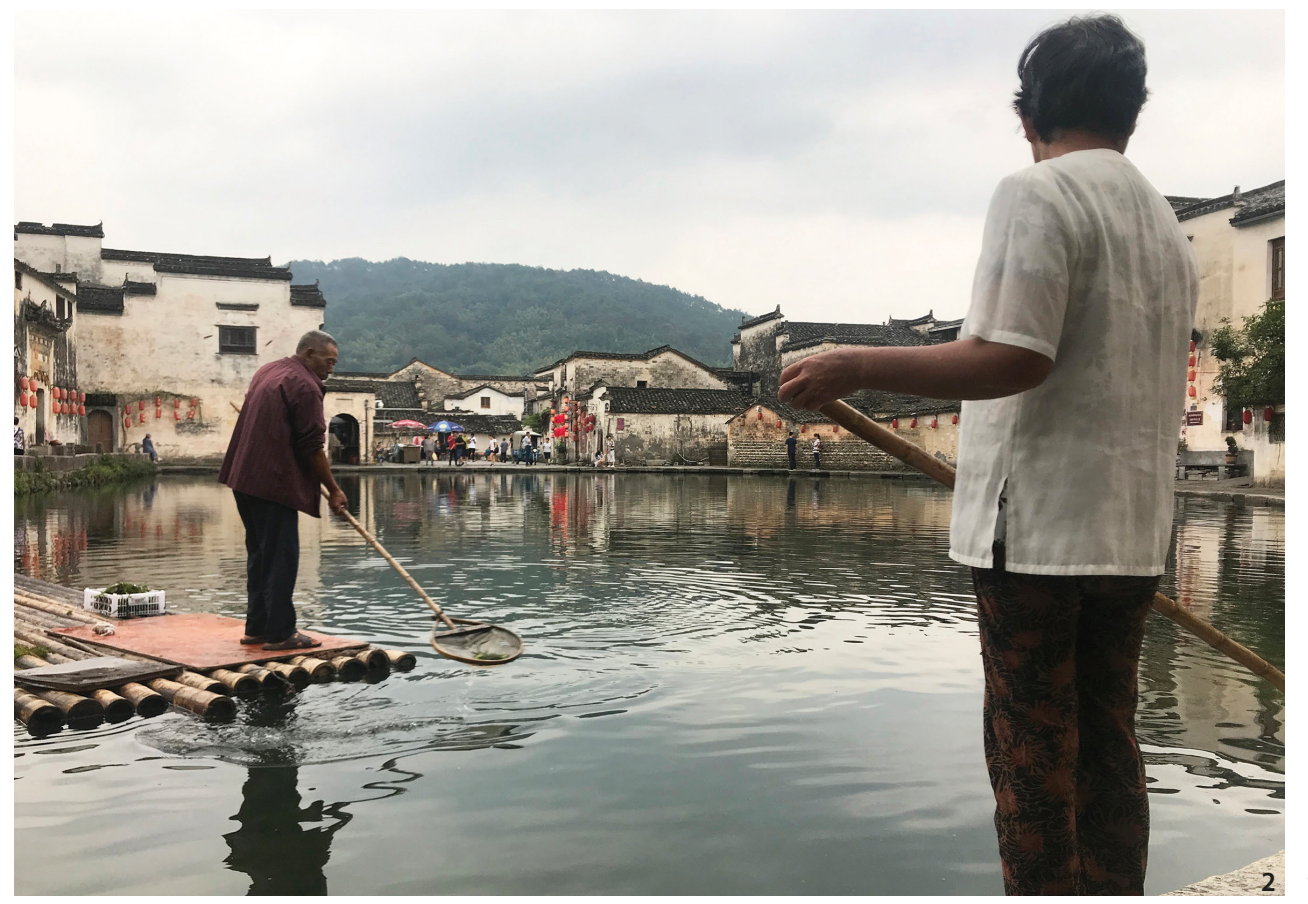

Figure 2 Hongcun Village, Yi County, Huangshan, Anhui Province, September 2018 (Source: the author). dedicated to safeguarding and promoting villages exemplifies this process (Figure 2).

In 2003, the first list of Chinese Historical and Cultural Towns \& Villages was issued (MOHURD 2003). Interestingly, the document borrowed its name from the Chinese Historical and Cultural Cities, an earlier list, drafted in 1982, that identified a group of historic cities to be preserved. Replacing the term 'cities' with 'towns' and 'villages', the 2003 list highlighted on the one hand the continuity with the previous document, while on the other, it emphasised a change of scale and a major shift in the national attention and consideration for settlements of smaller size.

Aiming to objectively evaluate the heritage of the villages, the list defines a precise set of criteria applicants should meet to be granted this title (NCHA 2003). Beginning with monuments and historical buildings (selected according to their historical value and state of conservation, building methods, and construction techniques), it further extends to include 'urban' landscape, in terms of built environment continuity and scale-in particular along historic streets or waterways-the consistency of the original urban layout, and integrity of the natural landscape and the environment with which the built heritage 'coexists' (State Council 2008). Interestingly, a few years later, these same factors would merge into the UNESCO discussion on Historic Urban Landscape (developing since 2005) that led to the official recommendation issued in 2011 (UNESCO 2011). It is to be noted that the inscription criteria proposed for the Chinese list also addresses the presence of the resident population in the core protected area ('life continuity'-shenghuo yanxu xing), which is perceived as an important positive element (NCHA 2003), marking a further step in the reflection on 'living heritage' that developed after the inscription of the historic cities of Pingyao and Lijiang on the Work Heritage List in 1997 (Lv and Wen 2018). The second part of the list template reviews about existing conservation measures, such as approved plans and lists of protected buildings. The attention paid to planning tools anticipates the revision of the Urban Planning Law, originally issued in 1990 and reissued in 2007 with the name Urban and Rural Planning Law (CPC 2007). As a result of this update, the practices of urban planning began to be formally applied to both rural and urban areas (Bray 2013).

What started in 2003 as a short list of just 12 villages, already tripled in 2005 and has steadily increased since, batch after batch, to reach the number of 276 settlements in 2014. At the beginning of 2019, four years after the previous update, the list has been renewed with a seventh batch. This last document that counts 211 additional villages, distributed especially among some less-represented provinces (Hebei, Henan, Hubei, Guangxi, Shandong), is almost equal to the total number of villages inscribed in the previous 15 years, confirming the growing importance attributed by the government to the built heritage of villages and, more broadly, to culture. Interestingly, this last dispatch states that the protection of the listed villages has 
to be combined with the improvement of the living environment and the promotion of traditional Chinese culture, a remark which gives further insights into the aims of such an inscription (MOHURD 2019).

The Ministry of Housing and Urban-Rural Development (MOHURD) and the National Cultural Heritage Administration (former SACH) are the main institutions in charge of coordinating this group of villages, which now totals 487 settlements.

In 2012, nine years after the first batch of the Famous Historical and Culture Villages was approved, a new list was issued. The press conference for the launch of the Chinese Traditional Villages provides a fascinating account of the reasons leading to the establishment of this new list of small settlements (SCIO 2013).

The country, it was said, is a thousand years old farming civilisation, and traditional villages have preserved the cultural roots that stemmed from the countryside. Such heritage is not renewable and is facing a crisis caused by the rapid urbanisation and industrialisation of the last decades. Therefore, although some villages might not have many ancient buildings, they embody, in their layout, in their location, and in many intangible aspects, the cultural elements that reflect the essence of Chinese culture probably even more deeply than ancient villages, because the ultimate scope is 'not the preservation of their material forms, but the inheritance of the culture that in those forms and places is expressed'. The 2012 list, therefore, intends to expand the scope of the previous one, protecting a larger number of villages. Accordingly, it defines a more comprehensive standard template of selection (MOHURD et al. 2012, 125).

Compared with the set of criteria of the earlier list, there are a number of new points worth noting. First of all, the document is articulated into three main categories of evaluation: traditional architecture, village layout, and intangible elements, whilst the previous list considered only heritage values and conservation measures. Throughout all the criteria, the new list emphasises regional and ethnic characteristics, local culture, and a 'local sense of beauty'. Accordingly, building techniques related with local traditions are more relevant if combined with skills and tools still applied in the construction of 'mundane buildings'. While only one point in the Famous Historical and Cultural Villages criteria takes into consideration intangible features (such as festivals, handicrafts, poems, legends, operas, and songs), here a full set of scores is devoted to these aspects. The document highlights the vitality of inheritance transmission, its dependency on local rituals and activities, and its link with the specific physical environment of the village and its surroundings. Crucially, the 'symbiotic' relationship between villages and their specific natural environment is broadly considered, both in the scientific and cultural aspects reflected in the site selection, and in its consistency with the agricultural landscape.

Further insight comes from the Guiding Opinions on Strengthening the Protection and Development of Traditional Villages, issued in 2012 by the Ministries in charge of the list. The text clearly highlights the pivotal role village heritage plays for three crucial aspects: the cultural awareness of the country and the enhancement of its cultural confidence; the preservation of the different cultures of all the ethnic groups and the safeguard of the 'completeness and diversity of Chinese culture'; and the economic improvement and sustainable development of rural areas (MOHURD, MOC and MOF 2012, 184).

This text clearly points out the strategic nexus that ties together rural heritage preservation, cultural identity interpretation, and poverty alleviation solutions. Such rationale accounts for the high number of villages included into this list that, at this moment, counts 4,153 villages, plus 2,646 other settlements comprised in a tentative fifth batch to be confirmed.

Worth noting is that the Ministry of Finance (MOF), which is in charge of this list with the Ministry of Housing and Urban-Rural Development (MOHURD), the Ministry of Culture (MOC) and the National Cultural Heritage Administration (NCHA), provides financial support to the villages included in the list. Besides financial assistance, a complete set of support and management mechanisms has also been established through the expert counselling of China's Traditional Village Protection and Development Research Centre, the Chinese Traditional Villages ArchiveBuilding and Surveys, and the publication of Requirements (MOHURD 2013) and Guidelines (MOHURD et al. 2014).

Put simply, at first, the notion of rural heritage was acknowledged (Chinese Historical and Culture Villages), then, it was extended from tangible to intangible values, from single objects to ensembles and landscapes, knowhows, and beliefs (Chinese Traditional Villages). This approach has also been perceived as a conceptual tool for the promotion of a more inclusive range of traditional settlements within a broader strategy of rural development ('revitalisation'-xiangcun zhenxing). Moreover, the presence of diversified forms of culture, many of them related to ethnic minorities, has been incorporated into the official discourse, transforming villages into precious archives of 
differences (cultural, social, biological). Villages and diversity therefore become vital elements in the redefinition of a more inclusive idea of 'Chinese identity', strengthening the cultural awareness of the nation and better positioning it on the global stage.

After the Chinese Traditional Villages list, a number of documents have been issued following this conceptual trajectory. The National New Urbanisation Plan 2014-2020, released in March 2014 by the Central Committee of the Communist Party of China, states that the Country:

should take into account the natural, historical, and cultural conditions of different regions and highlight regional differences, promote diversity, and avoid homogeneity; cities and towns should have distinctive historical memories, cultural contexts, and regional and ethnic features so that we can develop a new model of urbanisation that reflects the reality and embraces diversity. (State Council 2014)

Similarly, in its 2015 revised edition, the Principles for the Conservation of Heritage Sites in China incorporates the growing attention to 'the cultural diversity of different ethnic groups, regions and of the vernacular cultural heritage with unique local features' (Lv 2014, 3) and clearly demonstrates that 'the targets of conservation have changed, and more emphasis has been placed on the social benefits of conservation, the links between conservation and social and economic progress, and the connections between conservation and urban and rural development.' (3).

\section{Rural Tourism-Beautiful Leisure Villages}

The 2013 Press Conference for the launch of the Chinese Traditional Villages expressed the will to increase the efforts in publicity and education on traditional villages. It was said that this would be realised with the participation of television and other forms of media through launching a series of promotional activities including documentaries to introduce the wider public to the charm of traditional villages and to raise awareness about their protection (SCIO 2013). Hence, just over a year later, the first broadcast made its debut on the national CCTV (Chinese Channel of China Central Television). Now at its fifth season, Nostalgia (jizhu xiangchou) is a serial documentary which met with great success among mainland and overseas Chinese audiences (China Press reported that the audience of the fourth season reached 1.668 billion people [Sui 2018]). Each season consists of 60 episodes, each describing a traditional small settlement-its current situation, its people, stories, traditions, ancestors' teachings-in search of the country's cultural 'genes', as underlined during the broadcast presentation on the CCTV website (CCTV 2019). Drawing the reader into the complex debates on the concept of rural nostalgia is an unnecessary diversion here, but worth mentioning is that the documentary touches upon a complex mixture of feelings, grappling with current rural problems and a sort of nostalgia for a bygone age, bypassing harsh memories. From these mixed emotions, the broadcast brings out a narrative of values embedded in the rural world that are worth transmitting to the younger urban generation. Rural heritage acts therefore as an important feature for domestic propaganda and educational work, and at the same time, it becomes an economic asset for local governments and tourism industries (Svensson 2016). This TV series is produced by the Central Propaganda Department of the CPC Central Committee and the State Administration of Press, Publication, Radio, Film and Television, it is included in the Chinese cultural heritage projects, and it is planned in close coordination with the Ministry of Housing and Urban-Rural Development (MOUHRD) and the National Cultural Heritage Administration (NCHA). The documentaries cover the vast majority of Chinese provinces, autonomous regions, municipalities, and special administrative regions. They portray a balanced number of rural traditions and minority cultures, framed within a cultural heritage narrative and a tourism agenda (Svensson 2016, Oakes 2012).

\section{Huanglingcun}

The opening sequence of the third and fourth season of Nostalgia shows a beautiful village on the mountains, lit by the warm colours of fruits drying on bamboo racks in the open air: Huanglingcun.

Due to its success in tourism, Huanglingcun is now probably the most famous village in Wuyuan County. It is an ancient settlement, surrounded by forest and terraced fields, boasting a 580 year-long history going back to the Xuande Emperor of the Ming Dynasty (14251435). However, since the late 1970s, Huanglingcun has experienced depopulation, and when Wuyuan County Rural Culture Development Co. Ltd. first began investing in the renovation of its old constructions in 2009, the village had been suffering from inadequate sanitation and power supply, backward infrastructure, dilapidated houses, and abandoned fields. In 2013, the company obtained the right to use $33,000 \mathrm{~m}^{2}$ of built land in the old village and built more than 90 new houses and apartments along the main road on the valley floor, allowing 

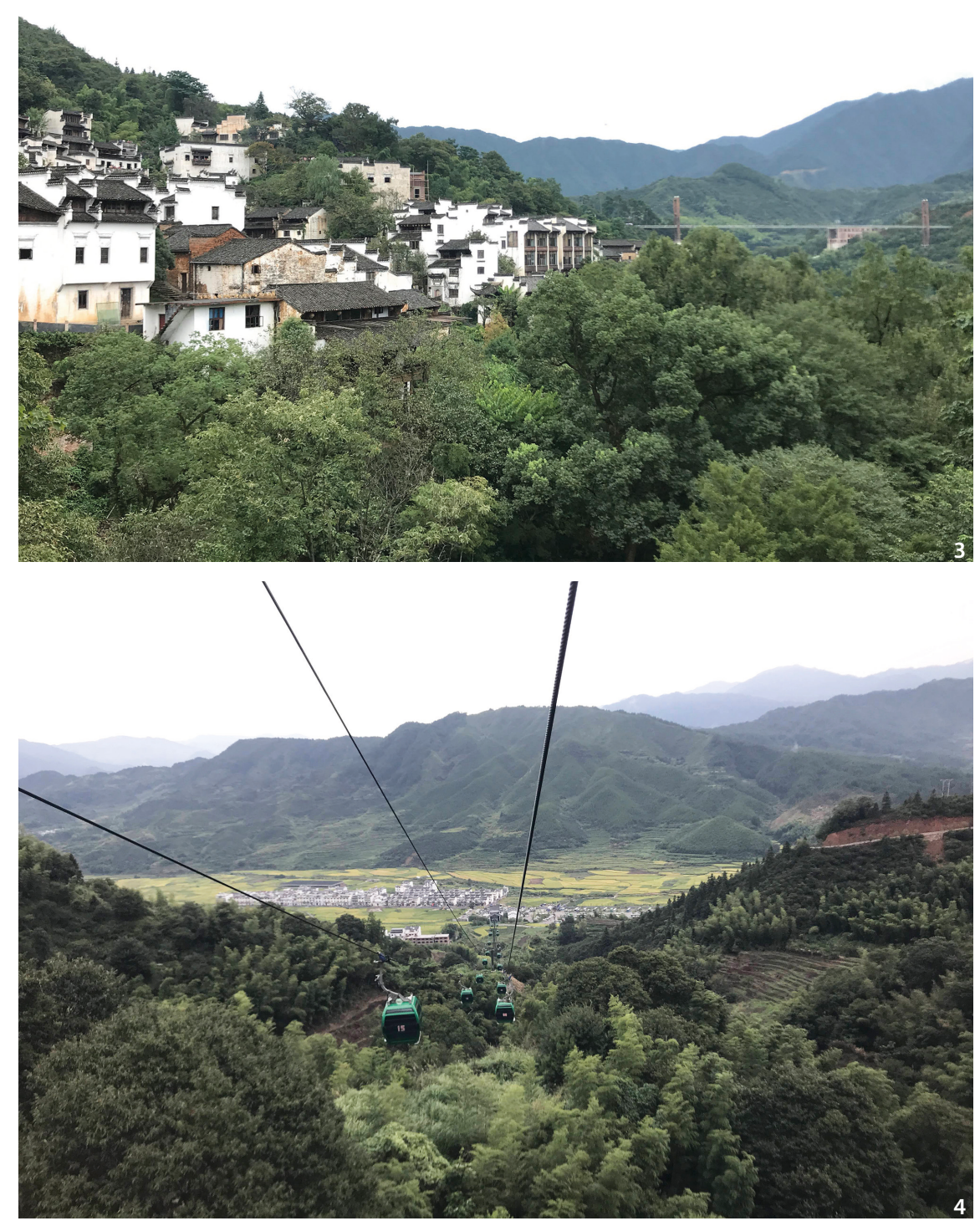

Figure 3 Huanglingcun village, Wuyuan County, Shangrao, Jiangxi Province, September 2018 (Source: the author).

Figure 4 The cable car to Huanglingcun Village, Wuyuan County, Shangrao, Jiangxi Province, September 2018 (Source: the author).

the inhabitants of Huanglingcun to replace their old house with a new one. Besides restoring existing buildings in the village, the company also increased the number of ancient structures by bringing historic houses from other counties and re-assembling them in the village. Of the 120 old buildings in the village, 30 actually came from different locations. Interestingly, the process of dismantling and reassembling Yixin Hall is documented through pictures and explanations displayed inside the building itself, which is now located at the gates of Huanglingcun and used as an exhibition hall. The Government of Xucun Town, where the building initially stood, still owns the right to use its spaces. The entrance fee to visit the village is $145 \mathrm{CNY}$ (September 2018) and the easiest way to access it is via cable car, built by the company and included in the ticket. Restaurants and shops are all arranged along the main street of the village, and retail mainly targets cultural and traditional market-related products, such as antiquities and old books, tea houses, bamboo crafts, calligraphy art, and paper umbrellas. Several buildings have been renovated into hotel accommodations, organised as an 'albergo diffuso' (a scattered hotel with a central reception area and rooms distributed in various historic buildings), while the remaining houses are mostly empty. Along with the renovation of the buildings, Wuyuan County Rural Culture Development Co. Ltd. was also responsible for the revitalisation of the landscape. Terraced fields are now planted with different crops following seasonality and the aesthetic expectation of visitors, and a path with panoramic platforms and a long glass bridge hanging over the fields complete the tourist experience. 
The heritage narrative is a crucial component of the promotion of villages and the relevant investments made for the transformation of Huanglingcun give an idea of the economic pressure on rural areas and its relationship with the tourism market (Figure 3 and Figure 4).

Tourism in China is a rapidly expanding market that is growing in parallel with the Chinese middle class and its increasing economic possibilities. This sector of the economy is perceived as an effective tool to fight the poverty that persists in marginal areas of the country by redistributing resources from the wealthy coastal cities inland. 'In the People's Republic of China (PRC), as elsewhere in the world, tourism is introduced in remote, rural, and ethnic regions as a modernising tool that can promote economic and cultural development and can better integrate minority populations within the nation-state.' (Cornet 2015, 29)

Rural tourism exploits natural environments, pastoral contexts, agricultural products, as well as rural heritage, popular traditions and ethnic cultures. It is intended to offer tourist visits, entertainment, and shopping opportunities while simultaneously boosting employment and increasing the income of farmers (MOA and CNTA 2010).

According to the National Tourism Development Report (MOC 2017), rural tourism in China is creating 10 million new jobs annually. In 2015, this sector experienced a growth of $60 \%$ with respect to the previous year. It is estimated that during the course of the $13^{\text {th }}$ Five Year Plan (2016-2020), the number of tourists in the countryside will increase $15 \%$ every year, and 150,000 villages will be recognised as rural tourism sites with an estimate of three million operators and four billion tourists in this sector alone (MOC 2017).

In 2014, under the $18^{\text {th }} \mathrm{CPC}$ Congress and the Ecological Civilisation and Beautiful China campaigns, the Ministry of Agriculture launched the China's Most Beautiful Leisure Villages and Beautiful Rural China project as an update of the Beautiful Villages experience, promoting 100 villages and 140 agricultural landscapes, examples of which being rose gardens or rare types of rice fields (Gao 2014).

A couple of years later, a new revised list was issued by the same Ministry (MOA 2016). China's Beautiful Leisure Villages once again promoted fundamental objectives such as protecting traditional dwellings, conserving ecological environment, expanding agricultural modernisation, and improving service facilities. Whilst the direct benefits for the village being included in the list are mostly in terms of formal recognition and publicity, the general rationale refers to inheriting the secular culture of farming-civilisation and encouraging rural economic potential, specifically addressing the rural tourism market. Accordingly, the list is divided into categories attempting to expand the types of villages that can take advantage of this initiative, further underlining the role of heritage as an engine of development: historical ancient villages, characteristic villages, modern new villages, and ethnic villages.

Wuyuan County is a pioneer in rural tourism strategy. In 2013, it was identified as an experimental zone for the development of this type of tourism (Qin 2013). Since then, the area has become a very popular destination due to targeted investments, infrastructure reinforcement (opening of railway station in 2015), and a successful communication campaign including the slogan: 'Wuyuan, the most beautiful village in China'. The County belongs to the ancient Huizhou Prefecture, so its historical roots are similar to the ones of southern Anhui-where Xidi and Hongcun are located - although nowadays it sits in a different province. Its hilly landscape is rich in rivers, trees and tea plantations, and is enclosed between the mountains of Dazhangshan, the World Heritage site of Huangshan, and Sanqingshan, the sacred mountain of Daoism and also a World Heritage site. The area counts about 30 villages already included between the two lists of Traditional and Historical Cultural Villages (several settlements are inscribed in both groups). Tourism success led to the promotion of new safeguarding regulations and favoured the implementation of the already existing ones. Agricultural landscapes and well-preserved villages are recognised as a system of complementary aesthetic values, but above all, they are perceived as commodities for tourist consumption and as such are adapted to market demands. Visitor flow intensifies during seasonal flowerings, with peaks in mid-March when rapeseed flowers are in bloom around the villages, and in the autumn with its flaming red maples. As a result, farmers are encouraged to grow ornamental crops like rapeseed, lotuses, grapes, and chrysanthemums. A ticket (costing from 60 to $145 \mathrm{CNY}$, depending on the number of villages or the days of visit) is necessary to visit the historic villages in the area. Profits are generally directly managed by large-scale tourism investment companies coming from cities that acquire the right to use terrains and dwellings in exchange for basic tourism services: ticket kiosks, parking facilities, toilets, information boards and etc. As exemplified in the case of Huanglingcun, such an economic model generally leaves little room for the development of the local community that obtains low income 


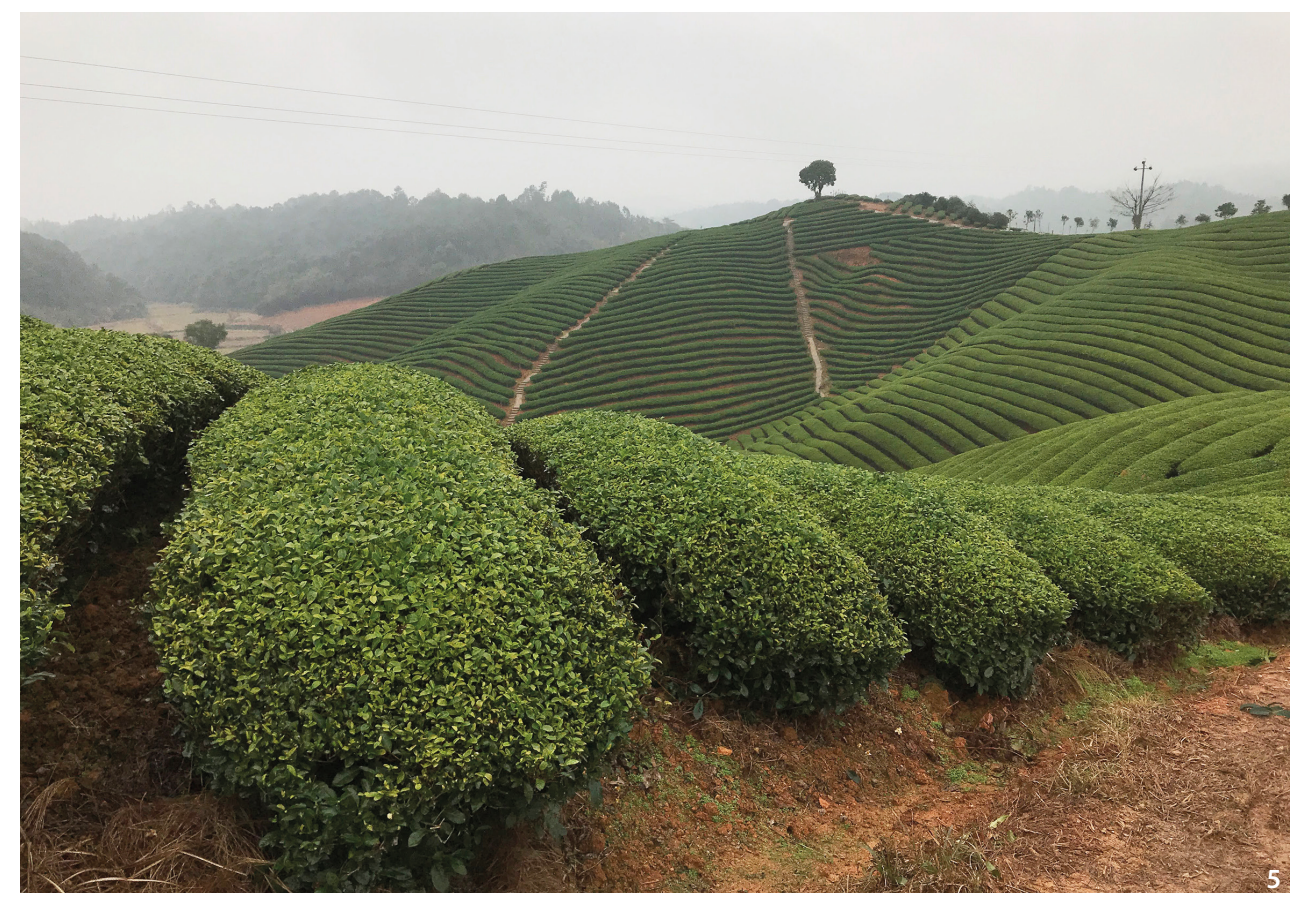

Figure 5 Tea plantation of the Dazhangshan Organic Tea Farmer Association, Wuyuan County, Jiangxi Province, December 2018 (Source: the author).

from compensation or low-level jobs in the tourism sector. In the past, this has resulted in tensions between locals, visitors, and the tourism enterprises that should act as engines of economic development (Wang 2014).

\section{Ecological Civilisation-Eco Villages Dazhangshan}

One specific experience in Wuyuan County stands out and is worth mentioning. On the foothills of Mount Dazhangshan, in China's 'golden triangle' of green tea production, approximately 235 local families, joined in an association, run a dozen of farms over an area of around 9,300 ha, of which 529 are designated for tea plantations.

The Dazhangshan Organic Tea Farmer Association combines local traditional farming practices with the most rigorous agro-ecological criteria for biological cultivations. In 2001, the association obtained the Fair Trade Certified label assigned by FLO (Fairtrade Labelling Organisation), the organisation that develops and reviews worldwide fair trade standards and assists producers in gaining and maintaining certification and in capitalising on market opportunities. Fair trade mechanisms ensure that farmers and workers receive, in addition to the price of their products, an extra sum of money (trade premiums) that goes into a communal fund to be invested in improving their social, economic and environmental conditions. Fair trade standards set regulations for capacity building and economic strengthening of the associations, as well as for applying democratic decision-making processes (producers have to democratically decide how to invest their fair-trade premiums). Thanks to the Law on the Selfgovernment of the Rural Population of People's Republic of China and their farming practices, the Dazhangshan families have met all requirements, becoming the first professional farmers' association in China to join an international organisation. Moreover, due to the certified organic quality of its tea leaves, sold also on the European market, the association is able to sell its tea to a price $30 \%$ higher than regular tea of the same type, netting an important additional gain. The entire surplus is managed and re-invested by the cooperative of farmers to further advance production (renewal of machinery, organic fertilisers ...), to support schools and education in the villages of the area (construction of students' dormitories, financial aid for school fees ...), and to improve their practices with training courses.

In summary, this working mechanism produces highquality organic green tea, takes care of the environment, and enhances community development. Moreover, the tidy rows of tea hedges shape a contemporary landscape that 'expresses a sense of beauty and equilibrium between nature and human culture. With these motivations, in 2019, the farmers' association was awarded the International Carlo Scarpa Prize for Gardens by the Benetton Foundation, a recognition given to a site, rich in natural, historical and creative values, which stands out for its practices of 'stewardship of the landscape' and 'care of places' (FBSR 2019). 
The success of the Dazhangshan experience is particularly significant in the Chinese context, considering two crucial issues the country is now addressing: the modernisation of the agricultural system, and environmental protection (Figure 5).

Since 2012, when the expression 'Ecological Civilisation' was first officially pronounced, it has become increasingly important in the national discourse and is now the main ideological framework of the contemporary Chinese environmental policies, as well as 'the most significant Chinese state-initiated imaginary of our global future' (Hansen, Li and Svarverud 2018).

The policy integrates environmental protection, China's agricultural tradition, and rural culture to address a new model of urbanisation that strengthens small inland cities which act as centres for smaller settlements and clusters of villages, to which they can provide the services that are lacking in rural areas.

Like in the previous cases, a demonstration list of villages was issued and evolved in time. The first list of ecovillages was launched in Hainan Province in 2000. The province has always been at the forefront for the ecological discourse in the country. In 1999, it was the first ecological demonstration province in China, and at the end of 2016, Hainan counted 17,270 Civilised Ecological Villages, a number that accounts for $82 \%$ of the villages in the province (Xiao et al. 2016).

In 2006, after the launch of the New Socialist Countryside policy, a list of Ecological Villages was created at the national level by the Ministry of Ecology and Environment (MEE 2006). In 2014, with the aim to implement the decisions of the $18^{\text {th }}$ National Congress of the CPC, the Eco-civilisation Villages list was released as an upgraded version of the previous one with new indicators for villages and small towns.

Purposes and objectives of these lists are in line with the documents and policies we have analysed so far: improve living conditions and increase farmers' income (rural tourism and farm accommodation are mentioned), strengthen the protection of heritage (tangible and intangible), conserve existing resources, and improve environmental conditions. Built heritage in villages is treated as an essential cultural component within a comprehensive concept of environment (MEE 2014).

Moreover, these lists add a targeted focus on the quality of agriculture and its products (quality of water, atmosphere and soil, circular agriculture, production of green and organic food), and on energy efficiency (alternative energy sources, waste recycling), with specific indicators and assessment methods. Most notable here is the nexus between environment, agriculture, and rural landscape. The heritage of farming culture is rediscovered as an asset to ensure not only food security and higher-value food, but also to maintain the rural landscape and to protect ecological environments and cultural heritage (State Council 2019). Yet, increasing the quality of agricultural products implies a shift from an economy of subsistence to one based on commercial exchanges that increases the income of individual farmers and contributes to the overall strategy of rural revitalisation and poverty alleviation. Recently, this approach is encountering a growing interest, not only inside the national boundaries, but also at a global scale, where China is becoming increasingly influential in the heritage and environmental discourses.

With a vast territory, different landforms and regional climates, and diverse cultures and agricultural histories, China possesses a wealth of rural landscapes. This richness has given the country a critical insight on the issue of landscapes at the global scale. This is reflected in the Chinese active responses to the Globally Important Agricultural Heritage Systems (GIAHS) initiative (launched by FAO in 2002) ${ }^{2}$, and in the country important role in the definition of the World Rural Landscapes project. This project was launched in 2017, by the International Scientific Committee on Cultural Landscape ICOMS-IFLA to foster worldwide cooperation in the study, management, and protection of rural landscapes. The document implements the 2012 UNESCO Florence Declaration on Landscape (UNESCO 2012) and considers that strengthening the safeguard of rural landscapes is an integral element of a sustainable development, since it enhances the quality of daily life, reinforces cultural identity, promotes work opportunity and participatory programmes, and preserves heritage assets (ICOMOS/IFLA 2017). The project takes into account the threats faced by rural landscapes, such as urban growth, abandonment of the land, intensive agricultural practices, and loss of traditional and local knowledge, while underlining the rising interest for its tourism and recreational use and demand for highquality food products.

The presence of Slow Food in China since 2015, and the seventh Slow Food International Congress held in Chengdu, October 2017, bear witness to the growing role of the country in this sector ${ }^{3}$.

Many other initiatives are being developed in China, opening up new opportunities and proposing innovative experiences that impact positively on the conservation 
of heritage resources. The pivotal role of these projects cannot be detailed here, but it certainly deserves to be better understood and studied ${ }^{4}$.

\section{Conclusions}

By reviewing the lists of villages and the criteria they set for small settlements, it is possible to outline a trajectory marking the progressive evolution of values and meanings attributed to heritage:

- In 2000, the inscription of Xidi and Hongcun in the WHL laid the foundations for the acknowledgment of the values assigned to rural settlements and vernacular buildings. This process was confirmed a couple of years later by the Chinese Historical and Cultural Villages lists and the subsequent publication of the 'Notice on Strengthening the Protection of Vernacular Architecture' in 2007.

- In 2012, the Chinese Traditional Villages list was released. This new list greatly extended the range of village values, to include settlement layouts and townscapes, intangible attributes and daily human activities (skills, practices, beliefs), landscapes, and agricultural practices (already anticipated by the 2008 'Guiyang Recommendations on Village Cultural Landscape Protection and Sustainable Use' and further supported by the inscription of the Honghe Hani Terraces in the WHL in 2013).

- Meanwhile, the campaign for the development of rural areas was launched and implemented. The Beautiful Villages initiative conveyed an idea of beauty based on a comprehensive concept of village environment that is expected to be clean (provided with infrastructures, underground utilities, clean energy, waste management) and good (in terms of quality of life, natural and cultural resources, organised layout). In this framework of development, the extension of the values assigned to traditional villages was a way to promote a higher number of settlements. The considerable increase of villages included in these lists stimulated the need to highlight local specificities, supporting and crucially sustaining the diversified expression of regional characteristics and ethnic cultures. Villages became precious archives of differences (cultural, social, biological, etc.) and Chinese culture became a more inclusive synthesis of multiple cultures, raising its appeal on the global scale.

- Immediately after, in 2016, the Beautiful Leisure Villages list was issued, upgrading the Beautiful Villages programme. This latter publication merges the criteria of the previous list with a focus on rural tourism. Tourism in remote, rural and ethnic regions is introduced as a modernising tool to promote economic and cultural development and to better integrate minorities within the nation-state. Accordingly, this strategy reinforces ethnic specificities as a resource for tourism promotion. Beautiful Leisure Villages also aimed to bolster agriculture and rural scenic areas.

- Environmental conservation, agriculture modernisation, and 'the Chinese heritage of farming culture' are the key issues of the Ecological Villages (later become Eco-civilisation Villages), since the Ecological Civilisation policy is now the main ideological framework of the current country's environmental policies and is encountering a growing interest on the international perspective (in 2017 World Rural Landscapes initiative by ICOMOS-IFLA and Slow Food Great China were launched).

The examples presented in this article show the complexity and interest of Chinese experiences in this field. While still relatively little discussed outside the country, it is argued that the path followed in China represents a model of rural revitalisation that will reverberate beyond the national borders for its convergence with the international debate on sustainable development (United Nations 2015; UN-Habitat 2016). Based on clear objectives, this process, connecting poverty eradication and development with heritage preservation and ecology, can be defined as a 'Chinese approach' to rural revitalisation and preservation.

\section{Notes}

1. Beautiful Villages and Beautiful Leisure Villages lists are managed by the Ministry of Agriculture (MOA); Historical and Culture Villages by the Ministry of Housing and Urban-Rural Development (MOHURD) and the National Cultural Heritage Administration (NCHA); Traditional Villages by MOHURD, NCHA, the Ministry of Culture (MOC), and Ministry of Finance (MOF); Ecological Villages and Eco-Civilisation Villages, by the Ministry of Ecology and Environment (MEE).

2. China at present has 15 GIAHS designated sites, outnumbering all other countries in the world (FAO 2018).

3. Slow Food is an international association founded in 1986 that promotes 'Good, Clean and Fair' food for all. The association is devoted to protect quality food, preserving agricultural biodiversity, conserving sustainable cultivation and traditional processing methods, and implementing farming techniques and markets in villages (Slow Village project).

4. The sections Village in the Landscape, Huanglingcun and Dazhangshan are based on the author's field 
work research and semi-structured interviews with officials and experts. The Village in the Landscape section builds on debates with experts from the Cultural Heritage Monitoring and Management Centre of West Lake, Hangzhou (field mission of October 2017) and documents given by the Cultural Heritage Monitoring and Management Centre of West Lake. The Huanglingcun section is based on interviews with experts from Wuyuan County Rural Culture Development Co., Ltd. and site visits (September 2018). The Dazhangshan section is based on site visits and interviews with employees from Dazhangshan Organic Tea Farmer Association, and experts from Benetton Foundation (December 2018).

\section{References}

AQSIQ (General Administration of at Quality Supervision, Inspection and Quarantine of PRC) and CNCA (Certification and Accreditation Administration of PRC). 2015. "Guidelines for the Construction of Beautiful Villages.” [Meili xiangcun jianshe zhinan.] Accessed 25 March 2019. http://www.cnis.gov.cn/ gbzqyj/201412/P020170705334688350160.doc

Bray, David. 2013. "Urban Planning Goes Rural: Conceptualizing the 'New Village"' China Perspectives 2013 (3): $53-62$.

CCTV (China Central Television). 2019. “Nostalgia' the First Season" ['Jizhu xiangchou' di yi ji.]. Accessed 25 March 2019. http://tv.cntv.cn/videoset/ VSET100216296129

Cornet, Candice. 2015. "Tourism Development and Resistance in China”. Annals of Tourism Research 52: 29-43.

CPC (Communist Party of China, Standing Committee of the Tenth National People's Congress of the PRC). 2007. Zhonghua renmin gongheguo chengxiang guihua fa [China Urban and Rural Planning Law of PRC]. Beijing, No. 74. October 29. Accessed 25 March 2019. http://www.china.com.cn/policy/txt/200710/29/content_9139139.htm

FBSR (Fondazione Benetton Studi Ricerche). 2019. “The Tea Gardens of Dazhangshan, The International Carlo Scarpa Prize for Gardens.” Accessed 25 March 2019. http://www.fbsr.it/en/landscape/the-international-carlo-scarpa-prize-for-gardens/sites-awarded/giardinidel-dazhangshan/

Gao, Li. 2014. "Result Annoucement of the Results of the China's Most Beautiful Leisure Villages and China's Beautiful Rural Landscape." [Zhongguo zuimei xiuxian xiangcun he zhongguo meili tianyuan tuijie jieguo jiexiao.] Accessed 25 March 2019. http://unn.people. com.cn/n/2014/1204/c14717-26149418.html

Han, Feng. 2018. "Introduction to the Special Focus Column.” Built Heritage 2 (3): 1-2.

Hansen, Mette Halskov, Hongtao Li, and Rune Svarverud. 2018. "Ecological Civilization: Interpreting the Chinese Past, Projecting the Global Future." Global Environmental Change 23: 195-203.

ICOMOS. 2000. "Ancient Villages in Southern AnhuiXidi and Hongcun." In Evaluation of Cultural Properties, 63-65. Paris: ICOMOS. https://www.icomos.org/ images/DOCUMENTS/World_Heritage/Volumes_ Evaluation/EN_Volume_d\%C3\%A9valuation_2000_ COMPLET.pdf

ICOMOS-IFLA. 2017. "Principles Concerning Rural Landscapes as Heritage. Adopted by the 19th ICOMS General Assembly." New Delhi, December 15. Accessed 25 March 2019. http://www.worldrurallandscapes.org/home/wrl-results/principles-text/

Lincoln, Toby, and Rebecca Madgin. 2018. “The Inherent Malleability of Heritage: Creating China's Beautiful Villages". International Journal of Heritage Studies 24 (1): 1-16.

Lv, Zhou. 2014. "Evolution of Cultural Heritage Conservation Philosophy Through the Lens of the Revised China Principles". National Heritage Centre of Tsinghua University, ICOMOS China, International Principles and Local Practices of Cultural Heritage Conservation. Conference Proceedings. Beijing. May 5-6, $1-10$.

Lv, Zhou, and Aiping Wen. 2018. "Interview, Lv Zhou: The Future and Development of Heritage Protection." [Fangtan, lü zhou: Yichan baohu de weilai yu fazhan.] Beijing Planning Review no. 3: 181-185.

Maags, Christina. 2018. "Disseminating the Policy Narrative of 'Heritage under Threat' in China." International Journal of Cultural Policy. Accessed 25 March 2019. https://www.tandfonline.com/doi/full/10.1080/102866 32.2018.1500559

MEE (Ministry of Ecology and Environment of PRC). 2006. "National Eco-Villages Establishment Standards." [Guojia ji shengtai cun chuangjian.] Accessed 25 March 2019. http://www.mee.gov.cn/gkml/zj/ wj/200910/W020061219369900638584.pdf

MEE (Ministry of Ecology and Environment of PRC). 2014. "Indicators of National Eco-Civilization Demonstration Villages and Towns." [Guojia shengtai wenming jianshe shifan cunzhen zhibiao.] Accessed 
25 March 2019. http://www.mee.gov.cn/gkml/hbb/ bwj/201401/W020140126555235763031.pdf

MOA (Ministry of Agriculture and Rural Affairs of PRC) and CNTA (National Tourism Administration of PRC). 2010. "Opinions of the MOA and the National Tourism Administration on Launching the Activities of National Leisure Agriculture and Creating Rural Tourism Demonstration Counties and National Leisure Agriculture Demonstration Sites." [Nongye bu guojia lüyou ju guanyu kaizhan quanguo xiuxian nongye yu xiangcun lüyou shifan xian he quanguo xiuxian nongye shifan dian chuangjian huodong de yijian]. Accessed 24 May 2019. http://www.moa.gov. cn/nybgb/2010/dbq/201806/t20180601_6150934.htm

MOA (Ministry of Agriculture and Rural Affairs of PRC). 2016. "The MOA Announces the 2016 Beautiful Leisure Villages." [Nongye bu gongbu 2016 nian zhongguo meili xiuxian xiangcun.] Accessed 25 March 2019. http://www.moa.gov.cn/xw/qg/201609/ t20160919_5278674.htm

MOC (Ministry of Construction of PRC) and NACH (National Administration of Cultural Heritage of the PRC). 2000. "Ancient Villages in Southern AnhuiXidi and Hongcun, Nomination of Properties for Inclusion on the World Heritage List." Accessed 25 March 2019. whc.unesco.org/en/list/1002/documents/

MOC (Ministry of Culture and Tourism of the PRC). 2017. "Annual Development Report of China’s Tourism." [Zhongguo lüyou fazhan baogao.]

MOF (Ministry of Finance of the PRC). 2014. "'Ten Models' Lead the Construction of Beautiful Villages" ["Shida moshi" yinling meili xiangcun jianshe]. Accessed 25 March 2019. http://www.mof. gov.cn/zhengwuxinxi/caijingshidian/zgcjb/201403/ t20140331_1061433.htm\#

MOHURD (Ministry of Housing and Urban-Rural Development of the PRC). 2003. "Notice on the publication of Chinese Historical Cultural Famous Towns (Villages) (first batch)" [Guanyu gongbu zhongguo lishi wenhua ming zhen (cun)(di yi pi) de tongzhi.] Accessed 25 March 2019. http://www.mohurd.gov.cn/ wjfb/200611/t20061101_157345.html

MOHURD (Ministry of Housing and Urban-Rural Development of the PRC), MOC (Ministry of Culture of the PRC), NCHA (National Cultural Heritage Administration of the PRC), and MOF (Ministry of Finance of the PRC). 2012. Zhufang chengxiang jianshe bu deng bumen guanyu yinfa "chuantong cunluo pingjia rending zhibiao tixi (shixing)" de tongzhi [Notice of the
Ministry of Housing and Urban-Rural Development and Other Departments on the Issuance of the "Traditional Village Evaluation and Identification Index System (Trial)"]. Accessed 25 March 2019. http://www. mohurd.gov.cn/wjfb/201208/t20120831_211267.html

MOHURD (Ministry of Housing and Urban-Rural Development of the PRC), MOC (Ministry of Culture of the PRC), and MOF (Ministry of Finance of the PRC). 2012. "Guiding Opinions on Strengthening the Protection and Development of Traditional Villages." [Zhufang chengxiang jianshe bu wenhua bu caizheng bu guanyu jiaqiang chuantong cunluo baohu fazhan gongzuo de zhidao yijian.] Accessed 25 March 2019. http://www.mohurd.gov.cn/wjfb/201212/ t20121219_212337.html

MOHURD (Ministry of Housing and Urban-Rural Development of the PRC). 2013. "Notice of the MOHURD on the Issuance of the Basic Requirements for the Preparation of Traditional Village Protection Development Planning." [Zhufang chengxiang jianshe bu guanyu yinfa chuantong cunluo baohu fazhan guihua bianzhi jiben yaoqiu de tongzhi.] Accessed 25 March 2019. http://www.mohurd.gov.cn/wjfb/201309/ t20130924_215684.html

MOHURD (Ministry of Housing and Urban-Rural Development of the PRC), MOC (Ministry of Culture of the PRC), NCHA (National Cultural Heritage Administration of the PRC), and MOF (Ministry of Finance of the PRC). 2014. "Guanyu qieshi jiaqiang zhongguo chuantong cunluo baohu de zhidao yijian." [Guidelines on Enhancing the Conservation of Chinese Traditional Villages.] Beijing, No. 61. April 25.

MOHURD (Ministry of Housing and Urban-Rural Development of the PRC), and NCHA (National Cultural Heritage Administration of the PRC). 2019. "Notice on the Publication of the 7th Batch of Chinese Historical Cultural Famous Towns and Villages." [Zhufang he chengxiang jianshe bu guojia wenwu ju guanyu gongbu di qi pi zhongguo lishi wenhua ming zhen ming cun de tongzhi]. Accessed 25 March 2019. http:// www.mohurd.gov.cn/wjfb/201901/t20190130_239368. html

NCHA (National Cultural Heritage Administration of the PRC). 2003. "Evaluation Criterion System of Chinese Historical Cultural Famous Towns and Villages." [Zhongguo lishi wenhua ming zhen ming cun pingjia zhibiao tixi.]. Accessed 25 March 2019. http://www. sach.gov.cn/module/download/downfile.jsp?classid $=0$ \&filename $=1609050915383658545 . \mathrm{doc}$ 
Oakes, Tim. 2012. "Heritage as Improvement: Cultural Display and Contested Governance in Rural China”. Modern China 39 (4), 380-407.

Qin, Haifeng. 2013. “The Country's First National Rural Tourism Holiday Experimental Area will be Established in Wuyuan.” [Quanguo shou ge guojia xiangcun lüyou dujia shiyan qu jiang zai wuyuan sheli.] Accessed 19 January 2019. gov.city.sina.com.cn/ zgjqdh/ sights/130905/1439_1357.html

Ruritage. 2019. "Ruritage: Rural Regeneration through Systemic Heritage-led Strategies.” Accessed 25 March 2019. https://www.ruritage.eu/

SAC (Standardization Administration of the PRC). 2014. "Guidelines for the Construction of Beautiful Villages, Preparation Instructions. Compilation manual of the National Standard." [Guojia biaozhun "meili xiangcun jianshe zhinan” bianzhi shuoming.] Accessed 25 March 2019. http://www.cnis.gov.cn/gbzqyj/201412/ P020170705334688350160.doc

SCIO (The State Council Information Office of the PRC). 2013. “The State Council Information Office Held a Press Conference on the Improvement of Rural Living Environment.” [Guo xin ban juxing gaishan nongcun ren ju huanjing gongzuo deng qingkuang fabu hui.] Accessed 25 March 2019. http://www.scio. gov.cn/ztk/xwfb/2013/gxbjxgsncrjhjjjqctclbhfzxwfbh/52928429306/Document/1348231/1348231.htm

State Council. 2008. "Regulations on Protection of Famous Historical and Cultural Cities, Towns and Villages." [Lishi wenhua mingcheng ming zhen ming cun baohu tiaoli.]. Accessed 25 March 2019. https://en.unesco. org/sites/default/files/china_regprotectionhiscities_ corof.pdf

State Council. 2014. "National New Urbanisation Planning 2014-2020." [Guojia xinxing chengzhen hua guihua.] Accessed 25 March 2019. http://www.gov.cn/ zhengce/2014-03/16/content_2640075.htm

State Council. 2015. "Opinions on Developing Electronic Commerce and Accelerating the Cultivation of New Motivation of Economic Development." [Guanyu dali fazhan dianzi shangwu jiakuai peiyu jingji xin dongli de yijian.] Accessed 25 March 2019. http://www.gov. cn/zhengce/content/2015-05/07/content_9707.htm

State Council. 2016. "Opinion of the General Office of the State Council on Supporting the Entrepreneurship Innovation of Returned Rural Residents and Promoting the Integrated Development of Rural First, Second and Third Industries." [Guowuyuan bangong ting guanyu zhichi fan xiang xia xiang renyuan chuangye chuangxin cujin nongcun yi'ersan chanye ronghe fazhan de yijian.] Accessed 25 March 2019. http://www.gov.cn/zhengce/content/2016-11/29/content_5139457.htm\#

State Council. 2019. “The General Office of the State Council \& the General Office of the Central Committee of the Communist Party of China issued 'Opinions on Promoting the Organic Connection between Small Farmers and Modern Agricultural Development." [Zhonggong zhongyang bangong ting guowuyuan bangong ting yinfa "guanyu cujin xiao nonghu he xiandai nongye fazhan youji xianjie de yijian.] Accessed 25 March 2019. www.gov.cn/gongbao/content/2019/ content_5370838.htm

Steiner, Achim, and Shenggen Fan. 2019. "Rural Areas are in Crisis. Revitalization is the Solution". Thomson Reuters Foundation News. Accessed 25 March 2019. http://news.trust.org/item/20190326150827-0ryhf/

Sui, Mingzhao. 2018. “The Fourth Season of 'Remember Nostalgia' Has More Than 3.8 Billion Global Visualization." ["Jizhu xiangchou" di si ji quanqiu dianji liang chao 38 yi.] Accessed 25 March 2019. http:// data.chinaxwcb.com/epaper2018/epaper/d6722/ d1b/201804/86363.html

Svensson, Marina. 2016. "Evolving and Contested Cultural Heritage in China: the Rural Heritagescape”. In Reconsidering Cultural Heritage in East Asia, edited by Matsude, A. and L. E. Mengoni, 31-46. London: Ubiquity Press.

UNESCO. 2011. "Recommendation of the Historic Urban Landscape." Accessed 25 March 2019. https:// whc.unesco.org/uploads/activities/documents/activity-638-98.pdf

UNESCO. 2012. "Florence Declaration on Landscape." Accessed 25 March 2019. http://iflaonline.org/wp-content/uploads/2014/12/FLORENCE-DECLARATIONON-LANDSCAPE-2012-6.pdf

UN-Habitat. 2016. "New Urban Agenda." Nairobi: UNHabitat. http://habitat3.org/the-new-urban-agenda/

United Nations. 2015. Sustainable Development Goals. New York: United Nations. https://www.un.org/sustainabledevelopment/sustainable-development-goals/

Wang, Hui. 2014. "Economic Analysis on Problems Derived from Rural Tourism 'Enclave Operation.' In Proceedings of the 2014 International Conference on Education, Management and Computing Technology, edited by Zhang H.M.

WHC (World Heritage Centre). 2000. "Ancient Villages in Southern Anhui-Xidi and Hongcun, 2000.” Accessed 
25 March 2019. whc.unesco.org/en/list/1002

Xi, Jinping. 2017. Secure a Decisive Victory in Building a Moderately Prosperous Society in All Respects and Strive for the Great Success of Socialism with Chinese Characteristics for a New Era. Beijing: Foreign Languages Press.

Xiao, Xiaochun, Yingling Wang, and Kang Liu. 2016. "Study on the Current Situation and Counter Measures of Ecological Civilization Construction in Hainan Province." [Hainan sheng shengtai wenming jianshe xianzhuang ji duice yanjiu.] Economic Research Guide no. 2: 65-67. 